\title{
You move, I watch, it matters: Aesthetic Communication in Dance
}

Guido Orgs ${ }^{1}$, Dana Caspersen ${ }^{3}$, Patrick Haggard ${ }^{2}$

Affiliations:

${ }^{1}$ Department of Psychology, Goldsmiths, University of London ${ }^{2}$ Institute of Cognitive Neuroscience, University College London

${ }^{3}$ The Forsythe Company

Corresponding author: Guido Orgs, Department of Psychology, Goldsmiths, University of London, SE14 6NW, London, UK. E-mail: g.orgs@gold.ac.uk

Book Chapter published in:

SHARED REPRESENTATIONS: SENSORIMOTOR FOUNDATIONS OF SOCIAL LIFE Sukhvinder S. Obhi \& Emily S. Cross, Editors, Cambridge University Press 2016. 


\section{Summary}

In this chapter we will introduce a new theory of aesthetics in the performing arts that is based on communication via movement. With a specific focus on dance performances, we propose that movement messages are communicated from performer to spectator. We suggest that the aesthetic impact of dance (and perhaps all performing arts) is a result of successful message-passing between performer and spectator. We show how Grice's four maxims of successful conversation can be applied to the performance situation. We propose that communication during a performance is interactive and bidirectional. Information being passed from performer to audience is primarily communicated through observed movement kinematics and choreographic structure: We will distinguish between the processing of syntactic information of postures, movements and movement sequences on the one hand, and processing of semantics of movement intentions on the other hand. Aesthetic processing of the movement message will further depend on the spectator's visual and motor expertise. In a dimensional model of aesthetic appreciation of dance we distinguish between processing fluency and novelty/complexity of information as two distinct sources of movement aesthetics that relate to specific brain mechanisms. Aesthetic judgements of preference and interest will reflect a combination of both implicit processing fluency and explicit aesthetic strategy of the observer. Our theory differs from existing accounts of aesthetic experience in that it emphasises successful communication as the primary source of aesthetic experience. Appreciation of dance in this context is neither just a function of dance movement features (as an objectivist aesthetics suggests) nor of the spectator's processing fluency (as a subjectivist aesthetics suggests). Instead, our emphasis on communication implies some level of experience-sharing between dancer and spectator. 


\section{Performing arts aesthetics and social cognition}

Aristotle argued that the performing arts are based on the human ability to imitate, and that spectators derive pleasure from witnessing imitations of reality (Poetics, IV). Aristotle thus emphasises social interactions between performers and between performers and the audience as a prime contributor to the aesthetics of the performing arts. The term 'aesthetics', derived from the Greek word "aisthetikos" (I sense, I feel) refers to the science of "sensual" as opposed to "rational" cognition and was initially coined by Alexander Baumgarten in the middle of the $18^{\text {th }}$ century (Hammermeister, 2002). The first empirical investigations into aesthetic cognition were conducted by Gustav Theodor Fechner (1871), who studied optimal proportions in paintings ("the golden ratio"). In more recent times, aesthetic perception and its neural basis has been investigated in the visual arts (Leder, 2004; Zeki and Lamb 1994) and in music (Koelsch, 2011). In this chapter we will focus on aesthetic percpetion in the performing arts and its link to social cognition and communication theory. We will argue that aesthetic perception of the performing arts involves successful communication between performers and spectators of a performance. More specifically we will combine the cognitive neuroscience of how we perceive and interpret other people's actions with knowledge from dance practice to formulate a neurocognitive theory of aesthetics in performing dance.

\section{Dance as a social art form}

What is dance? The Oxford English Dictionary gives a straightforward definition: Dance is "a series of steps and movements that match the speed and rhythm of a piece of music". This simple definition seems appealing at first glance, but regular visitors of dance performances, dancers and choreographers are likely to disagree: A dance performance will very often neither involve a series of steps nor any obvious relation to a piece of music, yet will clearly qualify as dance. Attempts to define core features of an art form are difficult because what qualifies as art constantly changes. The most appreciated art works today were often dismissed when they were created (Gopnik, 2012). To avoid these pitfalls, we will not focus here on trying to define what dance is, in the sense of giving minimal necessary and sufficient conditions. Instead, we aim to develop a neurocognitive theory of how dance works. That is, if, anything were to count as dance, we anticipate it would involve the cognitive and neural mechanisms that we describe here. We conceptualize the performing art of dance as a human socio-cultural activity where one individual moves, and another watches. Our definition differs from the conventional "Movement to music" definition in almost all possible respects, bar one. First, we hold that music is accessory, while one widespread view considers it essential. Second, we hold that the presence of an observer is an essential part of dance as a performing art, yet dance observation barely figures in most dictionary definitions of dance. This is not to say that one cannot dance without being watched; rather we argue that movement in performing dance serves a communicative purpose, it is expressive 
movement, geared towards exchanging emotions, intentions and ideas between people (Leach, 2013).

In our view, the key feature of dance as a performing art is not so much the dancer, but the dancer-observer dyad. People move all the time. What distinguishes a dance performance from mere movement is that it is intended for and has a receiver. It is movement designed for watching. Performing dance is thus an intrinsically social art form that involves at least two people, the dancer and a viewer. There is often a third person: the choreographer. In collaboration with the dancer, the choreographer designs the movement that is to be watched. We argue that understanding the aesthetic impact of dance involves first and foremost understanding how people see, process and interpret the movements of others.

In a neurocognitive sense, perceiving another's movement involves a perceptuomotor coupling between individuals' brains (Rizzolatti and Craighero, 2004; Heyes, 2011; Keysers and Perrett, 2004). Accordingly, the aesthetic experience of dance can be considered as a communicative process: In its simplest form, the dancer/choreographer is the transmitter of the message, body movement provides the message itself, and the spectator is the receiver of the message (see figure 1). From this perspective, dance is similar to other forms of communication and message-passing. In this paper, we will investigate how theories of communication deriving from cognitive informatics may help us to understand the aesthetic and cultural impact of dance.

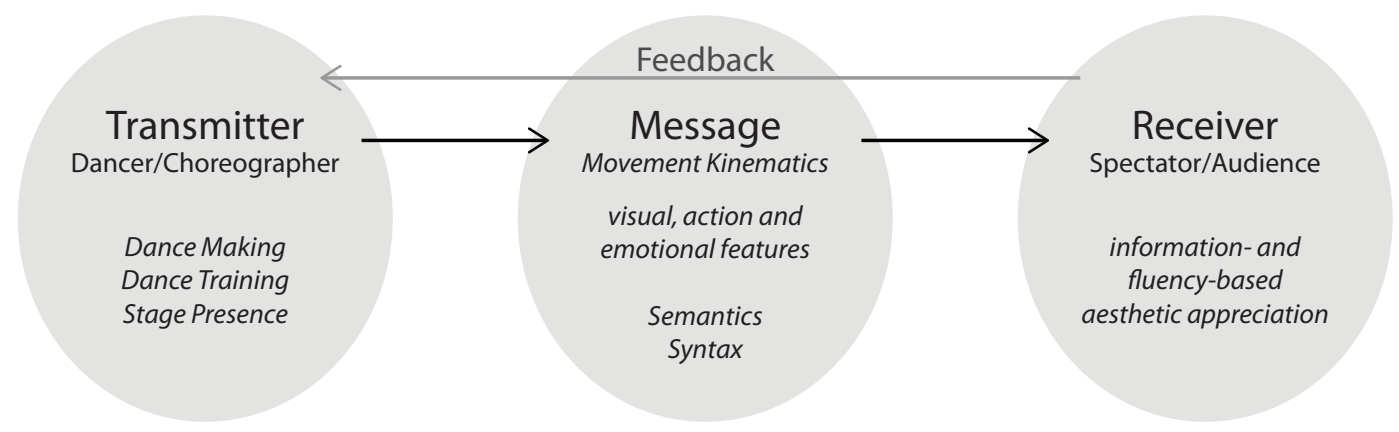

Figure 1: Communication during a dance performance.

Considering of dance as message-passing between bodies has a number of interesting implications. First, it clearly distinguishes dance from other art forms that involve inanimate artistic objects or representations, either visual (such as painting, art or film) or auditory (music). The cardinal activity of communication is the direct contact between two or more people, which is always present in dance. In contrast, cultural activities such as writing or painting may have undeniable artistic value, but the direct contact between artist and audience is not central. Rather, the audience relates to the artist only indirectly, through an artistic 'work' such as a book or painting. In dance, the communicative situation is the work.

Second, our view focuses on bodily movement as a core feature of all performing arts, including not only dancing, but perhaps also acting, miming, and singing 
Understanding how movement comes to carry aesthetic information therefore provides a basis for understanding how the performing arts work in general. This does not mean that movement is the only carrier of information during a dance performance, still less in other forms of performance art. Additional elements (costume, lighting, stage design, music, words etc.) will substantially contribute to the aesthetic experience of a dance performance. However, we contend that these additional elements are not strictly necessary: observed movement remains the only necessary and sufficient core for dance.

\section{Roadmap}

In the first part of this chapter we will characterize the three components of a communication theory approach to dance: the message transmitter (dancer and choreographer), the message (observed movement) and the receiver (the audience). We will then explore the constraints of message-passing by applying Grice's (1989) four cooperative principles of successful communication. These principles relate to the quantity and quality of information that is exchanged and determine the complexity of the movement message in choreography. Finally we will introduce a dimensional model of the aesthetic experience of dance that will relate the movement message to aesthetic judgement and will identify both implicit as well as explicit sources of aesthetic appreciation of movement.

\section{The Dancer as Transmitter}

In a communication theory approach to dance, the dancer's primary role is to convey a message to the audience by making body movements. This implies a certain level of objectification: The dancer uses his body as the tool for messagepassing. This view clearly distinguishes between performative dance on the one hand, and other movement practices such as Yoga, dance therapy and the martial arts on the other. The former focuses on successful communication to an audience, while the latter focus more on achieving a desired personal state, or goal. Psychologically, one might say that the goal of dance performance is primarily to induce a state of mind in the spectator. In contrast, the goal of dance therapy, and of some movement practices often associated with dance, is primarily to induce a state of mind in the dancer.

\section{Dance Training serves to optimise message transmission}

The limits of what can be communicated through dance are set by the physical constraints of the human body. In a communication theory approach to dance, the purpose of dance training is to reduce those constraints by expanding and refining the ways in which a body can move. This increases the message-passing capacity of dance, in the same way as expanding and refining the semantic and syntactic capacity increase the communicative capacity of the developing child. The increase in movement repertoire through dance training may involve addition of new movements that were not previously possible (Daprati, Iosa, Haggard, 2009; Calvo-Merino, Glaser, Grèzes, Passingham, Haggard, 2005) or may involve perfecting movements that are made everyday. In either case, the 
range of physical and emotional expression is increased. This idea resembles Rudolf Laban's developments of specific exercises "to develop the body as an instrument of expression" (Laban, 2011). Interestingly, this definition of dance expertise is not exclusive to any particular dance style or technique (such as HipHop or Indian Kathak), but only refers to a dancer's ability to effectively communicate intentions through movement.

\section{Choreographer vs. Dancer}

In the case in which dancer and choreographer are not the same person, the dancer will assume an additional role in transmitting not only his or her own intentions but also the intentions of the choreographer. In this section we will discuss the division of labour between Choreographer and Dancer in (a) generating messages, and (b) receiving them/reconstructing intentions.

\section{Generating messages}

The division of labour between dancer and choreographer in generating messages is variable and changes according to the methodologies chosen for creating and performing work. The messages communicated in a dance work are affected by numerous elements. Among these are the chosen movement sequences, categories or generation principles, the overall temporal and spatial structures of the work, the relationship of the movement to any sound component and the conditions of the environment within which the performance takes place. According to the method chosen to create the work, these elements may be the work of the choreographer or the performer, or they may be the product of differing levels of collaboration between the two (or more) people involved (Caspersen, 2004).

We illustrate this point with examples from one modern choreographer. William Forsythe's work shows several different divisions of labour between choreographer and performer. In "The Vertiginous Thrill of Exactitude," Forsythe choreographed set movements in a specific relationship to the music. The audience sees movements that are largely the creative work of Forsythe, which are embodied in the experience and sensibilities of the dancer. On the other hand, in "Sider," Forsythe and his fellow company members worked together and in parallel, using several different methods to create a body of motion ideas and scenic parameters. These parameters combined allow for the real-time emergence of motion content. In this piece, the dancers wear earpieces and listen to the soundtrack of a film of a Shakespeare play, which acts as a musical entrainment device. At the same time, Forsythe uses the earpieces to communicate with the dancers, directing the temporal and dynamic structure of the scenes. Within this framework, the dancers make decisions that shape the content of the work in performance, according to the strategies that have been established. What the audience sees is movement that results from one indivisible flow of ideas from numerous sources.

There are many ways to make dance, ranging from asking questions - as for example in the work of Pina Bausch (Climenhaga, 2009) - to applying mathematical rules (de Keersmaeker and Cvejić, 2013). Dance pieces often 
emerge from an extended period of artistic research rather than linearly from a preformed conception. In the process of dance making, neither dancer nor choreographer may be able to explicitly identify the artistic message that is being created and communicated. In fact underdetermined, conflicting or ambiguous messages may form an essential part of all art (Jakesch and Leder 2009; Kirk, 2008). Similarly, whereas some choreographic decisions and tools will be deliberately applied, others may be purely intuitive (for a selection of contemporary approaches to dance making see motionbank.org). Importantly, however, we argue that dance making - irrespective of the specific approach taken - ultimately results in a movement message that will prime the spectator to decode both content as well as the source of the message. Only the dancer can be both carrier and source of the movement message: the choreographer's contribution to the movement message requires the dancer's body as a carrier. Without the dancer, the choreographer can imagine message-passing, but cannot actually do it.

\section{Receiving messages}

During a dance performance, direct communication occurs only between dancer and spectator. The choreographers' and/or the dancer's contributions to the message are not directly discernible. Rather, the audience must recover the intentions of the message based on what they see. A strength of the communication approach to dance aesthetics is that it clearly distinguishes between the message the audience receives, which is based solely on the dancer's movements, and the message that is intended or generated, which is in the mind of the choreographer or dancer. Dance itself is the process of connecting the generative message to the receptive message.

\section{Movement as Message}

We have previously introduced a hierarchical model of dance perception that distinguishes three levels of movement representation (Orgs, Hagura, Haggard, 2013). Based on this model, we will identify body-specific and more general visual features of the movement message. We will show how these contribute to aesthetic impact of dance, separating at least three distinct levels of movement representation: static body postures, dynamic movement and sequential structure.

\section{Action features of the movement message}

Taken together, the building blocks of movement are combined in order to communicate intentions. This is impressively documented in studies showing that people attribute specific and elaborate mental and emotional states to dynamic animations of simple geometric shapes (Heider and Simmel, 1944). Kilner (2011) distinguishes four levels of movement representation: the motor level (neural motor commands), the kinematic level (space, time, force), the goal level and the intentional level. Since the motor commands, goals and intentions of the dancer are not available to the spectator directly, aesthetic communication between dancer and spectator can only occur at the visible kinematic level. In 
other words "the dancer consists - at least for his audience - of nothing but what can be seen of him. His properties and actions are implicitly defined by how he looks and what he does. One hundred sixty pounds of weight on the scales will not exist if to the eye he has the winged lightness of a dragonfly" (Arnheim, 1974). Although, auditory cues may play some part in perceived effort of movement (e. g. breath, contact with the floor), the primary carrier of the aesthetic impact of dance therefore lies in the visually perceived kinematics of the dancer's movements. The contributions of other levels of movement representation to the aesthetic experience of dance such as goals and intentions can only be inferred from the visually available kinematic level. Importantly, recovering these intentions and goals may require a special processing of the movement message within the motor system of the observer's brain (Rizzolatti and Craighero, 2004; Keysers and Perrett, 2004; Urgesi, Calvo-Merino, Haggard, Aglioti, 2007; Calvo-Merino, Urgesi, Orgs, Aglioti, Haggard, 2010; Orgs, Bestmann, Schuur, Haggard, 2011). Dance traditions have added other elements, such as costume, music and narrative. Nevertheless, the core of performative dance remains sensorimotor coupling induced by observing the dancer's movements and their kinematics.

\section{Emotional features of the movement message}

In addition to action goals and intentions, observers readily infer emotional expressions from both static and dynamic displays of the human body (de Gelder, van den Stock, Meeren, Sinke, Kret, Tamietto, 2010). Interestingly activity in body-specific visual areas such as the superior temporal sulcus (STS), or the fusiform body area (FBA) is increased for expressive (e.g. fearful) compared to neutral actions (Grèzes, Pichon, de Gelder, 2007; de Gelder, Snyder, Greve, Gerard, Hadjikhani, 2004), suggesting a role of these areas in inferring emotions from observed human movement. Emotional body postures additionally activate premotor areas of the brain (Grèzes, Pichon, de Gelder, 2007). Since these areas are also thought to extract intentions from others' actions, emotion and intention processing may be related. Expressive body postures are also processed faster than neutral body postures, producing shorter latencies in the body-specific N170 event-related potential, relative to neutral postures (van Heijnsbergen, Meeren, Grèzes, de Gelder, 2007). These findings suggest a direct link between expressiveness of movement and the ease with which the observed action is processed. The ease or fluency of stimulus processing has proven an important predictor of aesthetic processing. We will return to the role of processing fluency when discussing the spectator as the receiver of the movement message.

\section{Visual features of the movement message}

Aside from these action-specific features, aesthetic perception of the movement message will also depend on features that are common to all visual aesthetic perception (Palmer, Schloss, Sammartino, 2013). The best-studied principle of this kind has been composition and balance in visual objects or pictures (Fechner, 1871; McManus, 1980). Aesthetic judgement of dance appears to follow the same rules as for other visual stimuli. Aesthetic judgements of dance postures (Daprati, Iosa, Haggard, 2009) and of dance movements (Orgs, Hagura, Haggard, 2013) were governed by principles of symmetry and balance. Visual 
"gestalt" principles, such as good continuation of movement, influence aesthetic judgements of movement kinematics (Orgs, Hagura, Haggard, 2013). In more complex situations, such as many dance performances, visual attributes, such as the spatial distribution of a group of dancers on stage and interpersonal synchrony, may also be aesthetically relevant (Loeb, 1986).

For example, the use of pointe shoes in classical ballet can be interpreted as a means to enhance the visual features of the movement message. Pointe shoes were introduced in the end of the $18^{\text {th }}$ century, to allow dancers to execute movements that involved placing their weight on the tips of their toes. Pointe shoes emphasise the movement message by visually lengthening the legs of the dancer: leg movements become salient.

Similarly, the use of épaulement in classical ballet can be interpreted as a means to enhance the visual features of the movement message. Épaulement is a set of complex relationships between the dancer's eyes, head, shoulders, hips, hands and feet; a series of curvilinear forms, or directed lines or volumes, in angled relationships. Épaulement visually extends the geometric angles within the body, directing attention beyond the body and into the surrounding space. One effect of épaulement is to expand and delineate the audience's sense of the space around the dancers, and the relationships between the dancers, the stage and the audience. (Caspersen, 2011)

\section{The Spectator as Receiver}

In order to understand the aesthetic impact of movement on the receiver we need to understand the brain process that underlie movement perception (Zeki and Lamb, 1994; Blake and Shiffrar, 2007; Allison, Puce, McCarthy, 2000). Aesthetic evaluation of dance inevitably begins with visual perception of body movement. Several recent studies have identified neural processes that underlie perception of static visual bodies (Peelen and Downing, 2007), of human movement kinematics (McAleer, Pollick, Love, Crabbe, Zacks, 2013), and of inferring intentions from other people's actions (Kilner, 2011). All these processes are potentially relevant to dance perception. Our aim in this paper is to identify specific neural processes that are essential for the core circumstances of dance: namely you move, I watch, and it matters. An extensive review of all aspects of the neuroscience of dance is beyond the scope of this paper (for reviews, see Blaesing, Calvo-Merino, Cross, Jola, Honisch, Stevens, 2012; Cross and Ticini, 2011). Here, we focus on the influence of prior experience on aesthetic processing, because this is perhaps the area where existing theories of aesthetic processing are most helpful. In the case of observed movement, the spectator's expertise will depend on both visual and motor familiarity with the movement message.

\section{Visual and motor familiarity with the observed movement}

Aesthetic perception will depend on whether movements are familiar to the observer. The influence of familiarity on aesthetic judgement is well documented 
in the "mere-exposure effect" (Zajonc, 1968). People like what they know. In the case of movement we need to distinguish between visual and motor familiarity with the observed movement. Movements that have been frequently observed are preferred to movements that have been seen less frequently (Orgs, Hagura, Haggard, 2013). The influence of visual familiarity on the spectator can explain why people prefer specific movement styles. This argument is particularly strong if a movement style relies on a relatively restricted movement vocabulary, as in classical ballet. This is because a restricted movement vocabulary will usually imply more repetitions of the same or similar movements, thereby increasing their visual familiarity. Visual familiarity can explain long-term "Zeitgeist" effects in aesthetic appreciation (Carbon, 2010). Original and unfamiliar choreographies may be initially rejected by the public, but can gain widespread recognition over time. One example is Stravinsky's "Rite of Spring" first staged by the Ballets Russes in 1913, which caused outrage at its premiere but is now regarded as a masterpiece (Berg, 1988).

We have seen that on the side of the transmitter the vocabulary is limited by what the dancer can do. One important theory of movement perception makes an even stronger prediction: if visual motion perception is an 'embodied process', in the sense of linking the observed actions of others to one's own motor repertoire, then the receiver must have the capacity to make the movement if their brain is to fully respond to it (Aglioti, Cesari, Romani, Urgesi, 2008; Calvo-Merino et al., 2005, 2006; Orgs, Dombrowski, Heil, Jansen-Osmann, 2008; Cross, Hamilton, Grafton, 2006). This is because unfeasible movements outside the motor repertoire cannot be mapped onto existing motor representations and are therefore motorically unfamiliar. Movement with low motor familiarity should therefore be less aesthetically pleasant than movements for which the observer has the corresponding motor representation (Beilock and Holt, 2007; Topolinski, 2010). Lack of familiarity should have negative aesthetic impact. Existing studies on perceptuomotor coupling during aesthetic perception of movement however have produced mixed findings on the relationship between motor familiarity and preference. Whereas some studies show that knowing how to perform a movement correlates positively with aesthetic preference (Beilock and Holt, 2007; Topolinski, 2010; Kirsch, Drommelschmidt, Cross, 2013) other studies suggest that novel movements outside of the motor repertoire of the observer are actually preferred to known movements. For example extreme body postures are preferred to less extreme postures (Cross et al., 2011, Daprati et al., 2009).

Visual and motor familiarity both contribute to the spectator's expertise. Expertise has been show to have a profound effect on aesthetic judgement (Augustin and Leder, 2006). We will return to the role of expertise in discussing the influence of fluent processing in aesthetic appreciation.

\section{Bidirectionality of communication}

In dance performance, information is exchanged from performer to audience, but also from audience to performer. This bidirectional communication lies at the heart of dance's status as a performing art. Even a "passive" audience provides 
continuous feedback that will influence dancers. For example, audience members may spontaneously clap or laugh, or even leave an on-going performance. Even lack of overt audience behaviour may be a signal to the dancer, indicating involvement and concentration. These audience reactions confirm whether the audience receives the message transmitted by the dancer, and further communicate whether the dancer's intentions were understood as intended by the dancer. For example audience laughter provides feedback to the dancer that their intention to be funny succeeded. Or if they had some intention other than being funny, the message of laughter provides feedback that the dancer's intention failed. This information from the audience can then be used by the dancer to modulate timing or expressivity of their movements, so as to either be less or more funny, as appropriate. Accordingly the feedback provided by an audience is used directly by the transmitter to adjust the communication process. The existence of such a feedback loop supports the view of a performance as mutual communication between performer and audience. This loop is unique to the performing arts, and is absent in other art forms that are not "live".

Some choreographers emphasise the bidirectionality of communication between performers and the audience by creating work in which the spectator can become part of the actual performance. A performance may take place among observers or outside the traditional theatre setting, thereby blurring the separation between performers and the audience. Examples for such an interactive approach to choreography can be found in the work of Meg Stuart/Damaged Goods (Peters, 2010).

\section{Dance as message-passing, or as experience-sharing?}

In this paper, we use the communication-theory view of dance to sketch an experimental approach to performing arts aesthetics. Defining dance as a communicative act places few constraints on what dance is, other than emphasising the importance of the receiver/audience. A communicative account of how dance works requires more precise constraints if it is to be more informative. A major shift in communication theory occurs if we compare the quantitative, mathematical formulations of Shannon and Weaver (1949), and the pragmatic, behavioural theories pioneered by Grice (1989). The original mathematical theory of information did not restrict in any way the set of messages that might be passed from transmitter and receiver, and required only that the set of messages be known in advance to both parties. In fact, however, human communication typically involves a contextual restriction on what is actually said. Think of the set of messages that you expect to exchange with the person who cuts your hair, for example, and the larger set of message that you do not expect to exchange. In the next section of this paper we show how Grice's cooperative principles for successful conversation (Grice, 1989) can also be used to understand how dancers communicate messages, and how audiences understand them. These cooperative principles relate to the (i) quantity of information (ii) the relation between packets of information, (iii) the manner in which information is presented and (iv) the quality of information. Message- 
passing in dance is highly culturally constrained, and a Gricean approach can help in understanding how these constraints work. Grice's maxims are reproduced in table 1, together with a suggestion of their possible application to dance.

\begin{tabular}{|l|l|}
\hline Maxim & Manifestation in dance \\
\hline Quantity & Movement vocabulary and dance style \\
\hline Relation & $\begin{array}{l}\text { Structural properties of the movement sequence, } \\
\text { complexity and novelty of composition. }\end{array}$ \\
\hline Quality & $\begin{array}{l}\text { Congruency between observed movement and } \\
\text { inferred movement intentions; stage presence }\end{array}$ \\
\hline Manner & $\begin{array}{l}\text { Semantic ambiguity and novelty of movement } \\
\text { intentions }\end{array}$ \\
\hline
\end{tabular}

Table 1: Grice's maxims of successful communication applied to dance.

\section{Quantity: the size of the movement vocabulary}

Quantity relates to the amount of information communicated. Messages should contain neither more nor less information than required. In the case of dance, this translates to economy of movement. Quantity of communication would determine how many movements are potentially performed by the dancer, that is the size of the movement vocabulary. In order for messages to be understood, transmitter and receiver need to share a common vocabulary: The movement vocabulary of dance is constrained by the physical limitations of the human body on one hand, and by choreographic decisions on the other hand. In this context dance styles can be regarded as higher-level constraints on the vocabulary. A small movement vocabulary will facilitate communication between dancer and spectator but will limit the range of what can be expressed. The rise of modern dance in the $20^{\text {th }}$ century can be interpreted as a deliberate expansion of the message set. A larger vocabulary allows for a greater range of expression. However, some of the extended vocabulary will be (initially) less accessible to the spectator.

\section{Relation: Movement patterns}

Relation refers to the appropriateness of information at a given point of the communicative process. Information should be relevant to the specific communicative situation. The most obvious way that this constraint appears in dance involves the sequential structure of the movement vocabulary. Indeed sequential structure is an important predictor of aesthetic preference in dance (Orgs, Hagura, Haggard, 2013; Opacic, Stevens, Tillmanns, 2009). On the receiver side, communication of relevant information will fulfill audience expectations, whereas irrelevant information will violate expectations. We propose that the aesthetic impact of dance will depend on balancing when structural expectations are violated or fulfilled. Excessive violation of such expectations is unrewarding (Wunderlich, Dayan, Dolan, 2012). Equally, excessive conformity to expectation through ordered repetition is monotonous and reduces any sense of involvement. Seemingly irrelevant or unpredictable information may therefore 
be important to induce an appropriate level of surprise (Berlyne, 1974), and avoid monotony.

The principles of quantity and relation combined determine the syntatic complexity and novelty of the movement message. Complexity relates to the amount of information that is communicated through a sequence of movements (Berlyne, 1974): A choreography with few restrictions on the potential movement vocabulary and few or no repetitions (e. g. a dance in which each movement is performed exactly once) is maximally complex and rich in information, but may be hard to follow. Contrastingly, in a choreography that consist of repetitions of a single movement only (such as Sufi Whirling), the information is maximally redundant and each individual movement contains only very little information. Compositional rules such as repetition can be applied at the local level and specify transitions between individual movements or body postures. The same compositional rules can also be applied at a more global level, that is, between longer movement phrases or sections of the choreography (Orgs, Hagura, Haggard, 2013). Berlyne (1974) argued that "optimal" aesthetic processing occurs at intermediate levels of complexity. We will return to the role of movement complexity in aesthetic experience when introducing our dimensional model of aesthetic experience.

\section{Manner: Ambiguity of expression}

The Gricean principle of manner states that perspicuous messages will be easier to understand than ambiguous messages. Dance movements vary widely in ambiguity. Whereas gestural movements communicate intentions very specifically (e. g. waving or hugging) dance is often characterised by movements that are abstract with no obvious verbal label or specific meaning. While ambiguity is normally considered to impair communication, it has long been considered to have an exceptional, even essential status in art. Indeed, Grice (1989) himself refers to the case of poetry in discussing ambiguity. In poetry,, ambiguity can showcase the artistry of the writer by suggesting a number of different though equally plausible interpretations of the same sentence. Similarly, ambiguity of movement meaning may allow the spectator to choose one interpretation with the greatest personal relevance, or to hold a number of possible interpretations in play. In either case, the receiver's choice or evaluation process brings something to the aesthetic process. Alternatively, the spectator may simply enjoy the multitude of possible interpretations. Accordingly, ambiguity of artistic messages is often intentional and part of the message content (Deborah Hay, 2000). Messages may be "perspicuously ambiguous". In contrast to perspicuous messages, ambiguous messages require that the receiver takes a more active role in recovering intentions from the message (e.g. choosing one interpretations or resolve message conflict).

Whether perspicuous or ambiguous messages are perceived as aesthetically pleasing therefore depends on the spectator's epistemic actions whilst watching dance. We will return to this issue in the next section when we discuss syntactic and semantic processing and the role of cognitive effort in aesthetic appreciation. 


\section{Quality: "truthful" movement and stage presence}

Successful communication requires that messages are genuine and not deceptive. In Gricean terms, this includes two specific rules: (1) "Do not say what you believe to be false" and (2) "Do not say for which you lack adequate evidence". The principle of quality therefore is a prerequisite for the other cooperative principles to come into play (Grice 1989) as its violation collides with the general assumption that communication should be beneficial to both transmitter and receiver. We propose that movement is perceived as genuine if the spectator perceives congruency between a dancer's intentions and his movements. Dance critics and dancers alike speak of performances as "authentic" or "compelling" or "believable" (good) as opposed to "fake" or "merely doing the steps" or "not feeling it" (bad). These comments suggest that an important element of aesthetic evaluation is perceived discrepancy between the observed movement and the intentions that they are supposed to communicate. The importance of congruency between intention and movement execution have previously been emphasized in embodied approaches to acting ("method acting" as developed by Constantin Stanislavki). In his seminal book "Creating a role" (p. 47) Stanislavski writes:

"Scenic action is the movement from the soul to the body, from the center to the periphery, from the internal to the external, from the thing an actor feels to its physical form. External action on the stage when not inspired, not justified, not called forth by inner activity, is only entertaining for the eyes and ears; it does not penetrate the heart, it has no significance in the life of a human spirit as whole"

Applying the same principles to dance, we argue that a movement intended to be decisive will not appear genuine if it is performed ineffectively, for example with a hesitant quality. Congruency between performed movement and inferred intention is therefore closely related to a performer's stage presence. In our communicative theory of performing dance aesthetics, stage presence is equivalent to the performer's power to communicate or 'the ability to penetrate the heart of the observer', and results from the performer being perceived as a consistently reliable source of the movement message.

\section{A dimensional model of aesthetic appreciation of human movement}

We have emphasised a unique feature of performative art, namely that the art object is nothing but the kinematics of observed movement. In communication theory, we would say that these kinematics are the sole message. For there to be an artistic experience, the receiver must process this message. In Gricean theory, this processing aims to recover the transmitter's communicative intention. Thus, the act of communication in performative arts involves a performer who provokes experiences in the receiver, the audience. The Gricean principles given above describe some of the constraints and assumptions that are required for this process to work. In this section, we develop a model of the processes within 
the receiver's brain that operate on the message to generate this artistic experience. At this stage, the transmitter vanishes from our concerns: they have already done their work in generating the message, and it is now up to the receiver to deal with it.

The effect of the stimulus on the receiver ultimately depends on how the receiver's brain processes the message. In the case of dance, we have identified visual, action and emotional features of the movement message. These features are transmitted through movement kinematics and combine to produce both the syntactic structure (Quantity and relation of information) and the semantic content (Manner of information, ambiguity) of a dance performance. We have further identified the observer's expertise, in particular visual and motor familiarity as an important factor in how observed movements are processed by the brain. In this section, we consider how processing of the movement message influences aesthetic outcomes.

\section{Dimensions of aesthetic experience}

How can we relate stimulus processing in the brain to the features of 'dimensions' of aesthetic experience. Osgood's 'semantic differential' method (Osgood, Suci, Tannenbaum, 1957) purported to identify three cardinal dimensions of all human experience: valence (likable or not), activity or passivity, and potency (strong or weak). Interestingly, many accounts of aesthetic experience recapitulate these general dimensions of all experiences, perhaps reflecting the fact that all experiences have some aesthetic component. Building on Osgood's work, Berlyne (1974) identified two dimensions that played a primary role in the aesthetic aspects of experience. The first dimension is captured by overtly aesthetic judgements beautiful/ugly, pleasant/unpleasant, liked/disliked. The second dimension relates to judgements about stimulus information and structure, such as orderly/disorderly, simple/complex and boring/interesting.

Interestingly, Osgood's third dimension (potency) has received little attention in experimental approaches to aesthetic experience. However, all current theories of aesthetic experience are based on the visual arts or music perception. Speculatively, we propose that potency relates to the genuineness of the movement message and the performer's power to transmit. Thus, potency may reflect the intensity of communication between performer and observer. This kind of potency would be specific to the performing arts. However, for present purposes and in agreement with existing views in experimental aesthetics, we will focus on the two established dimensions of aesthetic experience, valence and activity.

\section{Brain mechanisms underlying aesthetic processing of movement}

We argue that these two dimensions of aesthetic experience relate to distinct brain processes. Aesthetic valence should strongly depend on processing fluency, whereas aesthetic arousal should primarily depend on brain mechanisms of novelty detection, both in the syntactic and the semantic domain. 


\section{Processing fluency}

The effect of the stimulus on the receiver ultimately depends on how the receiver's brain processes the message. The "fluency" of cognitive processing is a major predictor of aesthetic experience and refers to the ease at which a given stimulus is processed by the cognitive system. A central idea is that a stimulus is fluently processed when brain structures are specifically tuned to the features of that particular stimulus. For example high contrast stimuli are preferred to low contrast stimuli because they are more easily recognized (Reber, Schwarz Winkielmann, 2004) and optimally activate primary visual cortex. According to processing fluency theory, it is therefore not objective stimulus features that give rise to aesthetic experience but only how these features are processed by the cognitive system. Zeki and Stutters (2012) show that the amount of activity a simple motion pattern induces in early visual areas is directly linked to its subjective beauty. Stimuli are preferred if they optimally stimulate dedicated brain areas, such as V5 for simple motion patterns.

\section{Fluent processing of movement}

In the case of watching dance, processing fluency of observed movements will be determined by the neural architecture that mediates movement perception. Several studies identified functionally specialised systems in the human brain for the perception of biological motion (Blake and Shiffrar, 2007), and intentional action (Fogassi, Ferrari, Gesierich, Rozzi, Chersi, Rizzolatti, 2005). Fluency theories would suggest that the stimuli that readily or optimally activate these brain mechanisms should generate particularly fluent processing, and should therefore be perceived as aesthetically pleasant (Reber, Schwarz and Winkielmann, 2004). The movement message should induce fluent processing if its visual, action and emotional features optimally excite those brain areas that are specialized for processing these features.

\section{Fluent processing of familiarity}

In addition processing fluency strongly depends on the spectator's expertise. We have seen that visual and motor familiarity strongly influence how observed movements are processed by the brain. According to processing fluency theory, familiar stimuli are preferred because they are processed faster and more efficiently (Reber, Wurtz, Zimmermann, 2004). In contrast to fluency that is based on specialized brain areas for low-level visual parameters (Zeki and Stutters, 2012), processing fluency for familiar movements arises from learning (Orgs, Hagura, Haggard, 2013). Once new neural connections have been established by a novel stimulus, these connections are more easily activated when the same stimulus is repeated (Hebb, 1949). Fluency theory therefore suggests that familiar movements should be perceived as aesthetically pleasant because they activate existing visual or motor representations automatically and with little cognitive effort. Processing fluency should be largest for movements that are both visually and motorically familiar. 
Processing fluency correlates positively with the valence dimension of aesthetic judgement. Fluently processed stimuli are judged to be more pleasant, beautiful and likeable than disfluently processed stimuli (Zajonc, 1968; Reber, Winkielmann, Schwarz, 1998). From an evolutionary perspective, the experience of fluent processing is perceived as pleasant, because it signals safety and a predictable environment. However, fluently processed stimuli may also become more boring since they do not provide new information (Berlyne, 1974).

\section{The limits of processing fluency}

Professional dancers have typically undergone years of training and acquired substantial motor skill. In most dance performances involving professional dancers, spectators will not be able to perform what they are observing. Whereas frequent spectators of dance performance may acquire substantial visual expertise with the observed movements, they will not acquire motor familiarity (Aglioti et al., 2008). Acquisition of motor familiarity requires performing and seeing an action at the same time (Keysers and Perrett, 2004; Heyes, 2010). Yet spectators clearly enjoy skill and virtuosity across dance styles, from breakdance to ballet. Indeed, some studies in movement aesthetics suggest an inverse relation between motor familiarity and preference: The more spectacular a movement, the more likely it is to be liked (Calvo-Merino, Jola, Glaser, Haggard, 2008). Similarly contorted body postures are preferred to less contorted body postures (Cross, Mackie, Wolford, Hamilton, 2011). This suggests that fluent processing of familiar movements is not the only relevant process that determines aesthetic appreciation of dance. We suggest that this second aesthetic component is based on novelty and virtuosity of movement. In order to understand how communicating and extracting information will influence aesthetic appreciation of dance, we need to look at brain mechanisms for novelty detection in both movement syntax and semantics.

\section{Novelty of movement syntax}

Berlyne (1974) emphasises the role of amount of stimulus information in aesthetic experience. He argues that the aesthetic impact of a stimulus crucially depends on an optimal level of arousal that is produced by intermediate levels of stimulus complexity. Stimuli that contain a lot of information are judged as more interesting than stimuli that contain less information. For example, Crozier (in Berlyne, [1974]) presented sound sequences that varied in information content. Simple sequences that repeated a small number of tones were judged to be less interesting than sequences that consisted of more tones with fewer repetitions.

The brain has dedicated mechanisms that process novelty and predictability of information. In the case of stimulus sequences, this has been studied extensively using the "oddball" paradigm and event-related brain potentials (ERP) in the human electroencephalogram (Picton, 1992). In the auditory domain, the oddball paradigm involves sequences of identical tones that are interspersed with less frequent tones. Importantly, these unexpected "oddball" tones will induce a positive deflection of the ERP approximately $300 \mathrm{~ms}$ after their presentation. Importantly, this component which has been termed P300 does 
not depend on physical stimulus identity but only on whether a stimulus has been predicted or not (Wacongne et al., 2011). The P300 therefore serves as an index of surprise. The experience of surprise is directly related to the amount of information a stimulus provides: Within a sequence of repeated events a novel stimulus contains more information than a previously encountered event (Gottlieb, Oudeyer, Lopes, Baranes, 2013).

In analogy to these simple sound sequences, appreciating dance involves (implicit) learning of compositional rules (Orgs, Hagura, Haggard, 2013). Accordingly, the size of the movement vocabulary and the relation between movements determine information complexity and novelty in dance. The same brain mechanisms of sequential information processing that apply to simpler stimulus sequences of sounds will therefore also apply to aesthetic processing of movement and should predict both perceived complexity of the sequence as well as its interestingness. Choreographies that induce surprise should be more interesting than choreographies that are structurally less surprising, but may not be necessarily perceived as pleasant.

\section{Novelty of movement semantics}

The second source of information in dance is movement meaning. Whereas meaning of gestures and goals in object-directed actions and gestures is clearly defined, dance often involves abstract movements that are ambiguous with respect to their goal or communicative content. Similarly to processing of meaning in language and music (Orgs, Dombrowski, Lange, Heil, 2006; Koelsch, 2011), movement semantics have been studied using event-related potential measures (Amoruso, Gelormini, Aboitiz, Alvarez González, Manes, Cardona, Ibanez, 2013). Actions that cannot easily be integrated into an existing semantic context, such as a businesswoman balancing on one foot in the desert (Proverbio and Riva, 2009) induce an "action-N400", that is a negative deflection of the ERP $400 \mathrm{~ms}$ after action observation. Similar N400 effects can be observed for speech-incongruent gestures, for example saying "tall" whilst gesturing "short" at the same time (Kelly, Kravitz, Hopkins, 2004). These findings show that processing of movement intentions is functionally different from processing of sequential movement structure as described above (P300). Extraction of movement meaning and extraction of movement structure depend on functionally distinct neural mechanisms. Violations of common action semantics and ambiguous movement intentions are common features in choreography. Particularly theatrical styles of performing dance (e. g. choreographer Pina Bausch [Climenhaga, 2009]) make frequent use of placing familiar actions in unfamiliar contexts, or alienate gestural actions from their originally clearly defined intentional purpose. We argue that such manipulations of action meaningfulness provide a source of "conceptual surprise" that is fundamental to the aesthetic impact of dance.

Combined processing of movement syntax and action meaning determine how much information the movement message contains, and how easy it is to extract intentions from it. Accordingly, we propose that these two components should determine complexity and interestingness of observed movement, and should 
correlate with the second dimension of aesthetic processing (Berlyne, 1974). This dimension can also be linked to a general concept of activity, as in the semantic differential literature (Osgood, Suci, Tannenbaum, 1957).

\section{Explicit aesthetic appreciation and judgement based on two dimensions of implicit aesthetic processing.}

The two dimensions of aesthetic processing (processing fluency and novelty/complexity of information) correspond to two dimensions of aesthetic judgement, assessing the valence (beauty / likeability / pleasantness) and aesthetic arousal (interestingness / complexity / ambiguity) respectively. Both dimensions are implicit sources of aesthetic experience since they depend on the neural architecture for visual processing of human movement. Since the receiver has very little control over the perceptual mechanisms that are triggered by observation of a specific movement, we argue that these implicit mechanisms are primarily under the influence of the transmitter. In creating the movement message, both dancer and choreographer choose how to stimulate the brain of the spectator.

The spectator however deliberately chooses an explicit strategy of aesthetic appreciation that may favour either fluency or novelty/complexity. The spectator may enjoy the cognitive challenge that is posed by high levels of movement complexity and ambiguity, or he may enjoy the experience of fluent processing that is induced by watching a familiar dance piece that induces optimal visual movement processing. Indeed existing research on the role of expertise in aesthetic appreciation has shown that experts invest greater cognitive effort before making aesthetic judgements (Müller, Höfel, Brattico, Jacobsen, 2010) and focus on stylistic and compositional features rather than evoked feelings (Augustin and Leder, 2008). A complex choreography of highly unfamiliar movements will only be appreciated if the spectator is prepared to invest considerable cognitive effort. In contrast, simple and familiar movement messages may be considered beautiful because they are easily accessible and communicate intentions clearly and unambiguously, allowing the spectator to relax and be entertained. Ultimately, aesthetic appreciation will therefore depend on how the spectator weighs the outcomes of implicit aesthetic processing (valence and arousal) according to his explicit aesthetic strategy (cognitive effort):

Our theory makes the following predictions:

1) At low cognitive effort, aesthetic appreciation will primarily depend on processing fluency. Aesthetic appreciation should therefore strongly correlate with affective aesthetic judgements of preference and likeability. Familiarity of the choreography will be a strong predictor of aesthetic appreciation whereas movement complexity and ambiguity will be less appreciated. Novices will tend to adopt a low cognitive effort strategy of aesthetic appreciation.

2) At high cognitive effort aesthetic appreciation will primarily depend on surprise that results from both high levels of information complexity and 
semantic ambiguity. Aesthetic appreciation is strongly predicted by judgements of interestingness, clarity and ambiguity. Experts will tend to adopt a high cognitive effort strategy of aesthetic appreciation.

\begin{tabular}{|l|l|l|}
\hline Movement Message & $\begin{array}{l}\text { Aesthetic } \\
\text { appreciation }\end{array}$ & $\begin{array}{l}\text { Aesthetic } \\
\text { judgement }\end{array}$ \\
\hline Clear/Simple/familiar & $\begin{array}{l}\text { Fluency }> \\
\text { Novelty/Complexity }\end{array}$ & Pleasant \\
\hline Complex/ambiguous/unfamiliar & $\begin{array}{l}\text { Fluency }> \\
\text { Novelty/Complexity }\end{array}$ & Unpleasant \\
\hline Clear/Simple/familiar & $\begin{array}{l}\text { Fluency < } \\
\text { Novelty/Complexity }\end{array}$ & Boring \\
\hline Complex/ambiguous/unfamiliar & $\begin{array}{l}\text { Fluency < } \\
\text { Novelty/Complexity }\end{array}$ & Interesting \\
\hline
\end{tabular}

Table 2: The relationship between characteristics of the movement message, aesthetic processing, appreciation and judgement.

Figure 1 illustrates our dimensional mode of aesthetic appreciation. It includes two dimensions of aesthetic processing, valence and activity. Processing fluency primarily influences aesthetic affect, whereas novelty of syntactic and semantic information complexity primarily influence arousal. The two dimensions of aesthetic processing are captured by two distinct dimensions of aesthetic judgement. These are based on Osgood's semantic differential and relate to interestingness and pleasantness of the movement message. We further propose a third level that reflects the receiver's strategy of aesthetic appreciation. At this level the receiver weighs information from the two sources of aesthetic processing (fluency and information complexity/novelty), depending on how much cognitive effort the spectator is prepared to invest into decoding the movement message.

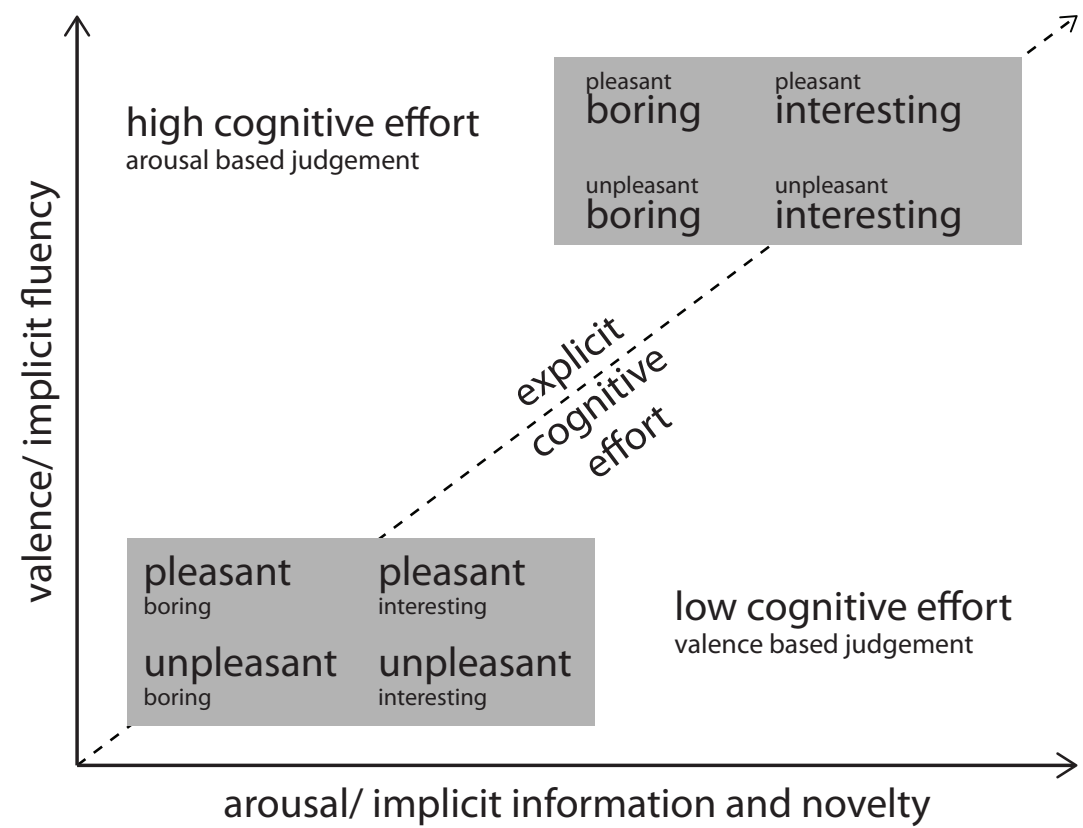

Figure 2: A dimensional model of the components of the receiver's appreciation of dance. 


\section{Is dance special?}

The analytic structure outlined here partially overlaps with art forms other than dance. Thus, the communicative process that we claim to underlie the aesthetic experience of dance may not be fundamentally different from the communicative processes that occur when attending a live music concert, for example. Existing models of music perception (e. g. Koelsch, 2011) can account for some of the structural aspects of how dance works, such as its composition across time. However, the crucial difference between dance and other art forms, such as music or acting, is that a given musical piece or play can be experienced independently of the human body that initially performed or created it. Dance does not produce anything else but observed movement. In contrast music and drama use movement as a means to produce either sound or spoken text. Their messages can therefore be described based on musical or literary characteristics and independent of the actions that originally produced these messages. Therefore, whereas watching human movement may indeed contribute to the appreciation of live music or theatre (Tsay, 2013) it is not essential to appreciate music or a play. Aesthetic perception of music will ultimately depend on the auditory characteristics of the music listened to and not on how the musicians move. In contrast, the unique quality of dance is that human movement is both necessary and sufficient for the key aesthetic experience.

\section{Conclusion}

During a dance performance, movement messages are communicated from performer to spectator. The aesthetic impact of dance (and perhaps all performing arts) is a result of successful message-passing between performer and spectator. Existing theories of aesthetic processing focus either on the message (objectivist view) or the receiver (subjectivist view) only. In contrast, we propose that aesthetic processing in dance is interactive and bidirectional. Further we claim that aesthetic information in dance is primarily communicated by the kinematics of observed movement. We distinguish between the syntactic complexity of postures, movements and movement sequences on the hand, and semantic ambiguity of movement intentions on the other hand. Aesthetic processing of both visual and motor features of the movement message will further depend on the spectator's own visual and motor expertise. In a dimensional model of aesthetic appreciation, implicit processing fluency and information complexity/novelty of observed movement interact with explicit cognitive effort. Aesthetic judgements of preference and interest will reflect a combination of both implicit aesthetic processing and explicit aesthetic strategy of the observer.

\section{Acknowledgements}

This work was supported by the 'Dance Engaging Science' grant from VW Stiftung, and by a research grant (F/07 134/DO) from Leverhulme Trust to PH. 
PH was additionally supported by a Professorial Fellowship from ESRC and by ERC Advanced Grant HUMVOL.

We are grateful to Scott Dela Hunta for advice and encouragement. 


\section{References}

Aglioti, S. M., Cesari, P., Romani, M., Urgesi, C. (2008). Action anticipation and motor resonance in elite basketball players. Nature Neuroscience, 11, 1109-1116.

Amoruso, L., Gelormini, C., Aboitiz, F., Alvarez González, M., Manes, F, Cardona, J. F., Ibanez, A. (2013). N400 ERPs for actions: building meaning in context. Frontiers in Human Neuroscience, 7:57.

Aristotle (1996), Poetics, Penguin Books, London, UK

Allison, T., Puce, A., McCarthy, G. (2000) Social perception from visual cues: role of the STS region, Trends in Cognitive Sciences, 4, 267-278,

Arnheim, R. (1974) Art and visual perception: A psychology of the creative eye. University of California Press, Berkeley, CA.

Augustin, D. M. \& Leder, H. (2006) Art expertise: a study of concepts and conceptual spaces, Psychology Science, 48, 135 - 156.

Berlyne, D.E. (1974) Studies in the new experimental aesthetics: Steps towards an objective psychology of aesthetic appreciation, Halsted Press, Jon Wiley \& Sons, New York, NY.

Beilock, S. L., \& Holt, L. E. (2007). Embodied preference judgments - Can likeability be driven by the motor system? Psychological Science, 18, 5157.

Berg, S. C. (1988) Le sacre du printemps. 7 productions from Nijinsky to Martha Graham. UMI Research Press, Ann Arbor.

Blake, R., \& Shiffrar, M. (2007). Perception of human motion. Annual Review of Psychology, 58, 47-73.

Bläsing, B., Calvo-Merino, B., Cross, E. S., Jola, C., Honisch, J., Stevens, C. J. (2012) Neurocognitive control in dance perception and performance, Acta Psychologica, 139, 300-308.

Carbon, C. C. (2010). The cycle of preference: long-term dynamics of aesthetic appreciation. Acta Psychologica, 134, 233-244.

Calvo-Merino, B., Glaser, D. E., Grezes, J., Passingham, R. E., \& Haggard, P. (2005). Action observation and acquired motor skills: An fMRI study with expert dancers. Cerebral Cortex, 15, 1243-1249.

Calvo-Merino, B., Grèzes, J., Glaser, D. E., Passingham, R. E., \& Haggard, P. (2006). Seeing or doing? Influence of visual and motor familiarity in action observation. Current Biology, 16, 1905-1910.

Calvo-Merino, B., Jola, C., Glaser, D. E., \& Haggard, P. (2008). Towards a sensorimotor aesthetics of performing art. Consciousness and Cognition, 17, 911-922.

Calvo-Merino, B., Urgesi, C., Orgs, G., Aglioti, S. M., \& Haggard, P. (2010). Extrastriate body area underlies aesthetic evaluation of body stimuli. Experimental Brain Research, 204, 447-456.

Climenhaga, R. (2009). Pina Bausch, Routledge, New York, NY.

Caspersen, D. (2004) 'The Body is Thinking', In Denken in Bewegung, Siegmund, G. (Ed.), Henschel Verlag, Leipzig,

Caspersen, D. (2011) 'Decreation: Fragmentation and Continuity.' In William Forsythe and the Practice of Choreography, Spier S. (Ed.), Routledge, London, pp. 93-100. 
Cross, E. S., Hamilton, A. F., Grafton, S. T. (2006). Building a motor simulation de novo: observation of dance by dancers. Neuroimage, 31, 1257-1267.

Cross, E. S., Kirsch, L., Ticini, L. F., \& Schutz-Bosbach, S. (2011). The impact of aesthetic evaluation and physical ability on dance perception. Frontiers in Human Neuroscience, 5, 102.

Cross, E. S., Mackie, E. C., Wolford, G., \& Hamilton, A. F. d. C. (2010). Contorted and ordinary body postures in the human brain. Experimental Brain Research, 204, 397-407.

Daprati, E., Iosa, M., \& Haggard, P. (2009). A dance to the music of time: Aesthetically-relevant changes in body posture in performing art. PLoS ONE, 4, e5023.

De Gelder, B., van den Stock J., Meeren, H. K. M., Sinke, C. B. A., Kret, M. E., Tamietto, M. (2010). Standing up for the body. Recent progress in uncovering the networks involved in the perception of bodies and bodily expressions. Neuroscience and Biobehavioral Reviews, 34, 513-527.

De Gelder, B., Snyder, J., Greve, D., Gerard, G. \&, Hadjikhani, N. (2004). Fear fosters flight: a mechanism for fear contagion when perceiving emotion expressed by a whole body. Proceedings of the National Academy of Sciences USA, 101, 16701-16706.

De Keersmaeker, A. T., Cvejić, B. (2013). En Atendant \& Cesena - A choreographer's score, Rosas, Brussels, Mercatorfonds, Brussels.

Di Dio, C., Macaluso, E., \& Rizzolatti, G. (2007). The golden beauty: Brain response to classical and renaissance sculptures. PLoS ONE, 2, e1201.

Fechner, G. T. (1871). Vorschule der Ästhetik. [Preschool of aesthetics] Hildesheim: Olms.

Fogassi, L., Ferrari, P. F., Gesierich, B., Rozzi, S., Chersi, F., Rizzolatti, G. (2005) Parietal lobe: From action organization to intention understanding, Science, 308, 662-667.

Forsythe, W. (2010). Improvisation technologies, Hatje Cantz.

Gopnik, B. (2012). Aesthetic science and artistic knowledge, Aesthetic Science: Connecting minds, brains and experience, Chapter 6, Oxford University Press, New York, NY. Edts. Shimamura, A. P., Palmer, S. E.

Gottlieb, J., Oudeyer, P. Y., Lopes, M., Baranes, A. (2013) Information-seeking, curiosity, and attention: computational and neural mechanisms. Trends in Cognitive Sciences, 17, 585-93.

Grèzes, J., Pichon, S., de Gelder, B., (2007). Perceiving fear in dynamic body expressions. NeuroImage 35, 959-967.

Grice, P. (1989). Studies in the way of words, Chapter 2: Logic and Conversation. Harvard University Press, Cambridge, MA.

Hammermeister, K. (2002). The German aesthetic tradition, Cambridge University Press, Cambridge, UK.

Hay, D. (2000). My body, the Buddhist. Wesleyan University Press, Middleton, CT.

Hebb, D. O. (1949). The Organization of Behavior. New York: Wiley \& Sons.

Heider, F \& Simmel, M. (1944) An Experimental Study of Apparent Behavior. American Journal of Psychology, 57, 243-259.

Heyes, C. (2011). Automatic Imitation. Psychological Bulletin, 137, 463-483.

Jakesch, M. Leder, H. (2009) Finding meaning in art: preferred levels of ambiguity in art appreciation. Quarterly Journal of Experimental Psychology, 62, 2105-2112. 
Kelly, S. D., Kravitz, C., and Hopkins, M. (2004). Neural correlates of bimodal speech and gesture comprehension. Brai and Language, 89, 253-260.

Keysers, C., Perrett., D. I. (2004). Demystifying social cognition: a hebbian perspective. Trends in Cognitive Sciences, 501-507.

Kilner, J. (2011). More than one pathway to action understanding. Trends in Cognitive Science, 15, 352-7.

Kirk, U. (2008) The neural basis of object-context relationships on aesthetic judgement. Plos One, 3, e3754.

Kirsch L. P., Drommelschmidt K. A., Cross E. S. (2013). The impact of sensorimotor experience on affective evaluation of dance. Frontiers in Human Neuroscience, 7:521.

Koelsch, S. (2011). Toward a neural model of music perception - A review and updated model. Frontiers in Psychology, 2, 110.

Laban, R. (2011). The mastery of movement, Dance Books Ltd., Alton, UK.

Leach, J. (2013). Choreographic Objects. Journal of Cultural Economy, doi:10.1080/17530350.2013.858058.

Leder, H., Belke, B., Oeberst, A., \& Augustin, M. D. (2004). A model of aesthetic appreciation and aesthetic judgments. British Journal of Psychology, 95, 489-508.

Loeb, A. L. (1986). Symmetry in court and country dance. Computers \& Mathematics with Applications - Part B, 12, 629-639.

McAleer, P., Pollick., F. E., Love, S. A., Crabbe, F. E., Zacks, J. M. (2013). The role of kinematics in cortical regions for continuous human motion perception. Cognitive, affective and behavioral neuroscience, ebub ahead of print.

McGregor, W. (2013). Choreographic thinking tools. Paul Hamlyn Foundation

McManus, I. C. (1980). The aesthetics of simple figures. British Journal of Psychology, 71, 505-524.

Müller, M., Höfel, L., Brattico, E., Jacobsen, T. (2010) Aesthetic judgments of music in experts and laypersons: an ERP study. International Journal of Psychophysiology, 76, 40-51.

Opacic, T., Stevens, C., \& Tillmann, B. (2009). Unspoken knowledge: Implicit learning of structured human dance movement. Journal of Experimental Psychology - Learning, Memory, and Cognition, 35, 1570-1577.

Orgs, G., Bestmann, S., Schuur, F., \& Haggard, P. (2011). From body form to biological motion: The apparent velocity of human movement biases subjective time. Psychological Science, 22, 712-717.

Orgs, G., Dombrowski, J.-H., Heil, M., \& Jansen-Osmann, P. (2008). Expertise in dance modulates alpha/beta event-related desynchronization during action observation. European Journal of Neuroscience, 27, 3380-3384.

Orgs, G., Hagura, N., \& Haggard, P. (2013) Learning to like it: Aesthetic perception of bodies, movements and choreographic structure. Consciousness \& Cognition, 22, 603-612.

Osgood, C. E., Suci, G.J., \& Tannenbaum, P. H. (1957) The measurement of meaning, Urbana, University of Illinois Press.

Palmer, S. E., Schloss, K. B., \& Sammartino, J. (2013). Visual aesthetics and human preference. Annual Review of Psychology, 64, 77-107.

Peelen, M. V., Downing, P. E. (2007). The neural basis of visual body perception. Nature Reviews Neuroscience, 8, 636-48. 
Peters, J. (2010). Damaged Goods/Meg Stuart. Are we here yet? Les presses du réel, Dijon, France.

Picton, T. W. (1992). The P300 wave of the human event-related potential. Journal of Clinical Neurophysiology, 9, 456-79.

Proverbio A. M., Riva, F. (2009). RP and N400 ERP components reflect semantic violations in visual processing of human actions. Neuroscience Letters, $459,142-146$.

Ramachandran, V. S., \& Hirstein, W. (1999). The science of art. Journal of Consciousness Studies, 6, 15-51.

Reber, R., Winkielman, P., \& Schwarz, N. (1998). Effects of perceptual fluency on affective judgments. Psychological Science, 9, 45-48.

Reber, R., Schwarz, N., \& Winkielman, P. (2004). Processing fluency and aesthetic pleasure: Is beauty in the perceiver's processing experience? Personality and Social Psychology Review, 8, 364-382.

Reber, R., Wurtz, P., \& Zimmermann, T. D. (2004). Exploring "fringe" consciousness: The subjective experience of perceptual fluency and its objective bases. Consciousness and Cognition, 13,47-60.

Rizzolatti, G. \& Craighero, L. (2004) The mirror-neuron system. Annu. Rev. Neurosci., 27, 169-192.

Shannon, C. E., Weaver, W. (1949). A Mathematical Model of Communication. Urbana, IL: University of Illinois Press

Stanislavski, C. (1968). Creating a role. NEL Mentor Books, London, UK.

Topolinski, S. (2010). Moving the eye of the beholder: Motor components in vision determine aesthetic preference. Psychological Science, 21, 12201224.

Tsay, C-J. (2013). Sight over sound in the judgment of music performance, Proceedings of the National Academy of Sciences, 110, 14580-14585.

Urgesi, C., Calvo-Merino, B., Haggard, P., Aglioti, S. M. (2007). Transcranial magnetic stimulation reveals two cortical pathways for visual body processing. Journal of Neuroscience, 27, 8023-30.

Van Heijnsbergen, C. C, Meeren, H. K., Grèzes, J., de Gelder, B. (2007). Rapid detection of fear in body expressions: an ERP study. Brain Research, 1186, 233-241.

Wacongne, C., Labyt, E., van Wassenhove, V., Bekinschtein, T., Naccache, L., Dehaene, S. (2011). Evidence for a hierarchy of predictions and prediction errors in human cortex. Proclamations of the National Academy of Sciences USA, 108, 20754-9.

Wunderlich, K., Dayan, P., Dolan, R. J. (2012). Mapping value based planning and extensively trained choice in the human brain. Nature Neuroscience, 15, 786-791.

Zajonc, R. B. (1968). Attitudinal effects of mere exposure. Journal of Personality and Social Psychology, 9, 1-27.

Zeki, S., Lamb, M. (1994) The neurology of kinetic art, Brain, 117, 607-636.

$\mathrm{Zeki}_{2}$ S., Stutters J. (2012). A brain-derived metric for preferred kinetic stimuli. Open Biology, 2:120001. 